\title{
Menopause and sexuality: characterization of sexual dysfunctions during climacteric, in women of Quindío (Colombia)
}

\begin{abstract}
Background: Climateric is a transitional phase, from a reproductive to non-reproductive stage in women's life; It generates a series of hormonal, organic, psychic, social and sexual changes. Regarding sexuality, women usually face alterations in sexual arousal, decrease in lubrication, pain during intercourse and less intense orgasms.

Objective: To characterize sexual dysfunctions and estimate the prevalence in a group of climacteric women in Quindío.

Materials and methods: Observational, descriptive and cross-sectional study. Consecutive sampling. Climacteric woman living in Quindío who had engaged in sexual activities in the last 6 weeks and went for a menopause and climacteric consultation to a private level III medical institution, in the city of Armenia (Quindío, Colombia); between July 2015 and June 2018. The IFSF-6 Questionnaire was used. Women with cancer, undergoing chemotherapy or radiotherapy, diagnosed psychiatric pathologies, illiterates and those who did not wish to participate were excluded. Data analysis was established with percentage frequencies, mean, median, ranges and averages \pm standard deviation.
\end{abstract}

Results: From a population of 684 women, $492(71.92 \%)$ were selected, and the questionnaire Female Sexual Function Index 6 (in English: 6-item Female Sexual Function Index) was applied. The average age was $57.18 \pm 5.43$ years. The mean age of onset of menopause was $49.13 \pm 3.28$ years. The average time in menopause was $8.15 \pm 2.98$ years. $1.43 \%$ had a history of early menopause. The prevalence of sexual dysfunction was $78.65 \%$. The main sexual disorders were difficulties with sexual arousal $(78.65 \%)$ and pain/ dyspareunia (66.46\%). The overall average, in the female sexual function index score, in the affected population, was $17.49 \pm 5.26$ points (range between 4.82 and 27.35 points). The median sexual dysfunction per woman was 3, which was present in $67.27 \%$.

Conclusion: The prevalence of sexual dysfunctions in climateric women from Quindío, is higher than $75 \%$ of the population, and is characterized mainly by difficulties with arousal and pain/ dyspareunia.

Keywords: menopause, sexuality, physiological sexual dysfunctions, women, prevalence
Volume 10 Issue 6 - 2019

Franklin José Espitia-De la Hoz

Sexological Clinic, Armenia, Quindío, Colombia Armenia

Sexological Clinic Quindío Colombia, Colombia

Correspondence: Franklin José Espitia-De la Hoz, Sexological Clinic, Armenia, Quindío, Colombia Armenia Sexological Clinic Quindío Colombia, Colombia, Tel 3127436696, Fax 7459490, Email espitiafrankli@hotmail.com

Received: November 14, 2019 | Published: December 23, 2019

\section{Introduction}

Climateric is a natural stage in women's lives, where a series of events that affect their well-being take place. It is characterized by the transition from the reproductive to the non-reproductive stage, due to the decrease and cessation of ovarian activity. It manifests about 1 year before, when hormonal changes and symptoms begin, up to 1 year after menopause, ${ }^{1,2}$ although it usually includes 2 to 8 years before and after menopause. ${ }^{3}$

Natural or physiological menopause is defined by the International Menopause Society (IMS) as the "permanent cessation of menstruation, determined retrospectively after 12 consecutive months of amenorrhea, without pathological causes". ${ }^{4}$

Despite not being exactly the same, climacteric and menopause are terms used interchangeably to name clinical events related to the decline and/or cessation of natural ovarian function, and it has been accepted as such.
Climacteric includes perimenopause (from the onset of symptoms to menopause), menopause and post menopause (from menopause to 60 years; in turn, it is subdivided into: early, covers the first 5 years of post-menopause: late, from 5 years after menopause, to 60 years). ${ }^{5,6}$

The average age of menopause in Europe varies between 50.1 to 52.8 years, in North America from 50.5 to 51.4 years, in Latin America from 43.8 to 53 years and in Asia from 42.1 to 49.5 years; ${ }^{7}$ therefore, a woman can spend, on average, a third of her life in post menopause; 8,9 since the life expectancy, of the current woman, is over 81 years.

As women complete the transition to menopause, about $85 \%$ have at least one symptom, such as: hot flashes, depressed mood or sleep disturbance, thus about $10 \%$ seek medical care. ${ }^{10}$

Reports from the Massachusetts Women's Health Study ${ }^{11}$ revealed that menopausal status is related to decreased desire and sexual arousal, in addition to dyspareunia 
Sexuality is a central aspect of the human being; although its essentially intended for reproduction purposes, it is also a source of pleasure and a natural relaxant, which reinforces self-esteem, intimacy and the relationship. According to the World Health Organization (WHO) it is defined as: "A central aspect of the human being, present throughout his/her life. It includes sex, gender identities and roles, eroticism, pleasure, intimacy, reproduction and sexual orientation. It is experienced and expressed through thoughts, fantasies, desires, beliefs, attitudes, values, behaviors, practices, roles and interpersonal relationships.". ${ }^{22,13}$

A sexual dysfunction is defined as the difficulty, during any stage of normal sexual activity, experienced by an individual or partner, for a minimum of 6 months; ${ }^{9,13}$ disorder that could negatively affect your sexuality and quality of life. Sexual dysfunctions encompass four types of sexual difficulties or disorders: orgasm, sexual arousal, sexual desire and pain. ${ }^{9}$ They occur in anyone, and their etiology is usually multifactorial, being determined by both internal and external factors. ${ }^{9,13}$

In Colombia there are few studies that have evaluated the behavior of climacteric in the sexual health of women, that is why the purpose of this study is to examine a group of climacteric, sexually active women from Quindío, both to characterize sexual dysfunctions, as well as to estimate their prevalence.

\section{Materials and methods}

\section{Design and population}

Observational, descriptive cross-sectional study; which included climacteric women from Quindio who had engaged sexual activity in the last 6 weeks, who went for consultation at the climacteric and menopause program from July 1, 2015 to June 30, 2018 in Armenia (Quindío, Colombia). The study was carried out in private, high complexity, private health institution (IPS/Institución Prestadora de Servicios) that takes care private and public health care patients. Women with cancer, undergoing chemotherapy or radiotherapy, diagnosed psychiatric pathologies, illiterates and those who did not wish to participate were excluded. Sampling was done consecutively with women who agreed to be part of the investigation. the Female Sexual Function Index 6 [(in English: 6-item Female Sexual Function Index (FSFI-6) ${ }^{14}$ was applied, which is a survey for women used for the detection of sexual dysfunctions.

The FSFI- $6{ }^{14}$ is a shorter version of the "Female Sexual Function Index (FSFI)"15 questionnaire. This tool contains an element from each of the six domains FSFI: desire, excitement, lubrication, orgasm, satisfaction and pain, making the application fast (3 minutes on average) and easier to measure. The domains of desire and satisfaction are scored from 1 to 5 points, and the other domains (excitation, lubrication, orgasm and pain) are scored from 0 to 5 points. The final score (total score: minimum of 2 and maximum of 30 ) is obtained by the sum of the weighted scores of each domain; the higher the score, the better the sexual function. ${ }^{15,16}$ The cut-off point for the risk of female sexual dysfunction is a score below 19 (sensitivity and specificity of 0.93 and 0.94 , respectively.) The simplicity of FSFI-6 makes it useful for office settings, facilitating the detection of the risk of sexual dysfunction in women. The version that is currently used is the one translated and validated in Ecuador by Chedraui et al. ${ }^{17}$ in 2012, which was used for this study.

\section{Process}

The recruitment of women was done by the gynecologist of the research group, who selected them during a medical visit part of the climacteric and menopause program. If they met the inclusion criteria and agreed to participate, the objective of the study was explained, and they were asked to fill in the informed consent. Once the consent was signed, a data collection instrument previously designed in Excel was applied; which included socio-demographic variables, sexual and reproductive health history as well as personal and family history. The confidentiality of the information provided was ensured. Subsequently, the professional nurse proceeded to complete the FSFI-6.

\section{Variables measured}

Sodium-demographic variables (age, race, marital status, occupation, place of origin, schooling, social security) were measured; height, weight, body mass index (BMI), habits (alcohol intake, consumption of psychoactive substances, smoking, sedentary lifestyle); in sexual and reproductive health (age of menarche, age of onset of sexual and obstetric life, number of sexual partners, age of menopause, time in menopause, sexual frequency, masturbation, oral sex, intercourse -vaginal or anal-, monthly frequency of sexual intercourse, time of living together, infidelity, history of sexual abuse or sexual violence in marriage and sexual dysfunction in the couple); history of chronic gynecological and surgical diseases. The FSFI6 score, as well as each of its domains, symptoms compatible with genitourinary syndrome, and complaints related to the menopausal transition were assessed.

\section{Statistical analysis}

A database was built in Excel. Data analysis was established with percentage frequencies, mean, median, ranges and averages \pm standard deviation. Data processing and analysis was done with the statistical software package SPSS version 17 (SPSS Inc. Chicago, IL, USA).

\section{Ethical aspects}

The study was presented in the clinic where the research was done, following the recommendations of the Declaration of Helsinki; being approved by the Ethics Committee prior to its execution.

\section{Results}

At the time of the study $492(71.92 \%)$ women were selected, from a population of 684 patients belonging to the menopause and climacteric program; $49(7.16 \%)$ refused to participate, $32(4.67 \%)$ were not sexually active, 25 (3.65\%) questionnaires were incomplete and $86(12.57 \%)$ filled them out incorrectly, so they were discarded.

The average age was $57.18 \pm 5.43$ years (between 45 and 72 years), and the couple's age was $63.17 \pm 6.49$ years (range between 36 and 87 years). It was observed that the studied group included mainly Hispanic, housewives, in domestic partnership, who had completed secondary education, had an urban origin and were overweight. $18.08 \%(\mathrm{n}=89)$ reported they were retired. Table 1 shows the sociodemographic characteristics in detail.

Of the patients, $23.78 \%(\mathrm{n}=117)$ presented 2 or more chronic pathologies. Endocrine pathologies were characterized by vitamin D deficiency $(49.39 \%)$, diabetes $(10.56 \%)$, hypothyroidism ( $8.73 \%)$ and hyperthyroidism (5.89\%). A sedentary lifestyle reported a prevalence 
of $72.15 \%(n=355)$ in the total of women, while $16.86 \%(n=83)$ were obese.

Table I Socio-demographic characteristics of climateric women with sexual disfunction, of Quindío

\begin{tabular}{|c|c|c|}
\hline & $\mathbf{n}$ & Proportion (\%) \\
\hline Age, $X \pm S D$ years & $57,18 \pm 5,43$ & \\
\hline Age of couple, $X \pm S D$ years & $63,17 \pm 1,49$ & \\
\hline Weight, $X \pm S D$ Kg & $65,83 \pm 7,53$ & \\
\hline Height, $X \pm S D$ meters & $1,64 \pm 0,16$ & \\
\hline $\mathrm{BMI}, \mathrm{X} \pm \mathrm{SD}$ & $24,69 \pm 1,61$ & \\
\hline \multicolumn{3}{|l|}{ Race } \\
\hline Hispánics, n (\%) & 238 & 48,37 \\
\hline Afro Colombian, n (\%) & 217 & 36,55 \\
\hline Indigenous, n (\%) & 37 & 7,52 \\
\hline \multicolumn{3}{|l|}{ Socio economic level } \\
\hline High & 127 & 25,81 \\
\hline Middle & 267 & 54,26 \\
\hline Low & 98 & $19,9 \mid$ \\
\hline \multicolumn{3}{|l|}{ Civil status } \\
\hline Married & 157 & 31,91 \\
\hline Domestic partnership & 259 & 52,64 \\
\hline Single/Divorced & 76 & 15,44 \\
\hline \multicolumn{3}{|l|}{ Occupation } \\
\hline Housewives & 295 & 59,95 \\
\hline Employees & 197 & 40,04 \\
\hline \multicolumn{3}{|l|}{ Health care plan } \\
\hline Private & 384 & 78,04 \\
\hline Public & 108 & 21,95 \\
\hline \multicolumn{3}{|l|}{ Origin } \\
\hline Urban & 392 & 79,67 \\
\hline Rural & 100 & 20,32 \\
\hline \multicolumn{3}{|l|}{ Educational level } \\
\hline Primary & 91 & 18,49 \\
\hline Secondary & 284 & 57,72 \\
\hline Technical & 65 & $|3,2|$ \\
\hline Professional & 52 & 10,56 \\
\hline
\end{tabular}

A prevalence of genital prolapses, $35.56 \%(n=175)$ was found, of which $65.14 \%(\mathrm{n}=114)$ were $\leq$ to grade II, $29.14 \%(\mathrm{n}=51)$ grade III and $5.71 \%(\mathrm{n}=10)$ grade IV (genital origin). Stress urinary incontinence was observed in $41.26 \%(n=203) .35 .36 \%(n=174)$ had undergone hysterectomy, $26.82 \% \quad(\mathrm{n}=132)$ had unilateral oophorectomy and $15.24 \% \quad(\mathrm{n}=75)$, bilateral. The most frequently associated urogynecological surgeries were colporrhagia with $36.99 \%$, and antiincontinence surgery with $24.59 \%$ was second.

Of the total population of women, $17.47 \%(n=86)$ admitted they were smokers, $88.82 \%(n=437)$ were social drinkers, while $5.89 \%(n=$ 29) admitted drug use.

The average age of the menarche was $12.49 \pm 1.86$ years (range between 11 and 20 years). The average age of menopause was $49.13 \pm 3.28$ years (range between 39 and 54 years). The average time in menopause was $8.15 \pm 2.98$ years (range between 3 and 27 years). $1.43 \%$ had a history of early menopause. $61.38 \%(n=302)$ were in early post menopause. Sexual orientation was predominantly heterosexual (90.24\%). 39.63\% ( $\mathrm{n}=195)$ were satisfied with their marital life.

Of the women, $77.43 \%(n=381)$ had initiated their sexual life between 13 and 23 years (median 17 years), 14.83\% $(n=73)$ between 24 and 29 years, and $7.72 \%(n=38)$ after 30 years. The median of the sexual partners in the total population was 3 (range between 1 and 9 partners) $48.17 \%(n=237)$ had had more than 6 sexual partners.

Of the population, $14.43 \%(\mathrm{n}=71)$ got pregnant before age 14 , and $11.78 \%(\mathrm{n}=58)$ had their first child before age 15 . The median age for the first child was 16 years, with a minimum of 13 years and a maximum of 36 years. The median of children was 4 (range between 1 and 13 children). $19.71 \%(n=97)$ had had at least one home birth. $3.25 \%(\mathrm{n}=16)$ reported the history of at least one instrumented delivery, and $64.63 \%(\mathrm{n}=318)$ reported the history of episiotomy. $11.99 \%(\mathrm{n}=59)$ reported at least one preterm birth; 39.63\% $(\mathrm{n}=195)$ had a history of at least one caesarean section. Of the total participants studied, $58.53 \%(\mathrm{n}=288 / 492)$ were large multiparas. $24.39 \%(\mathrm{n}=120)$ had aborted at least once, of which $70.83 \%$ (n 85/120) were treated in a health institution, $20.83 \%$ were induced by the patient herself and $8.33 \%$ in clandestine conditions.

Of the women, $21.34 \%(\mathrm{n}=105)$ had reported sexual abuse and violence at some point in their lifetime, where $11.42 \%(n=12 / 105)$ stated nonconsensual intercourse with partner, at least on one occasion; $18.49 \%(\mathrm{n}=91)$ had a history of a sexually transmitted infection. $38.41 \%(n=189)$ reported that the partner had been unfaithful. $26.21 \%$ $(n=129)$ claimed to have been unfaithful, at least on occasion.

Of the total population, $14.63 \%(\mathrm{n}=72)$ reported having coital activity less than once a month. Sexual frequency indicated a median of 2 intercourses per month (range between 1 and 12), representing $60.97 \%(n=300) .87 .19 \%(n=429)$ had 1 intercourse per sexual encounter, $23.78 \%(n=117)$ had 2 per encounter, while only $9.14 \%$ $(n=45)$ had 3 or more times per encounter. $13.61 \%$ emphasized the use of erotic toys.

At the time of the study, $67.27 \%$ said they avoided sexual intercourse and used all kinds of excuses. $39.43 \%$ were concerned about the loss of sexual intimacy. $83.94 \%$ said that sexual activity was important in their lives. $27.84 \%$ said that sex was still important in their lives, and they wanted a higher sexual intercourse frequency (median 2 times per week). 33.53\% stated being concerned about their children knowing they were sexually active. $98.78 \%$ assumed sexual activity as essential for marital success. 
Sexual practices were characterized as follows: $100 \%$ practiced vaginal sex, $74.39 \%$ oral sex and $11.38 \%$ anal sex. Masturbation is considered a common practice in $78.45 \%$ of women. Condom use was present in only $19.73 \%$ of single or divorced women. $38.41 \%$ of the total population of participants said they had not used a condom or contraceptive during their first sexual intercourse.

When characterizing sexual dysfunctions, according to FSFI6 , the overall prevalence was $78.65 \%(n=387 / 492)$, characterized by difficulties with sexual desire $[78.65 \%(n=387 / 492)]$ and pain / dyspareunia $(66.46 \%, n=327) .71 .95 \%(n=354)$ reported sexual dissatisfaction (Table 2).

The overall average, in the FSFI-6 score, for the entire participating population, was $19.95 \pm 5.87$ points (range between 4.82 and 27.35 points); while in the affected population, it was $17.49 \pm 5.26$ points (range between 3.76 and 17.92 points). The highest score was observed in the pain/dyspareunia domain (pain or discomfort during coital penetration) (3.89 \pm 1.57$)$, and the lowest in the desire domain $(2.78 \pm 0.89)$; the most conserved was the orgasm domain (Table 2).

Table 2 Female Sexual Function Index 6 (FSFI-6)], of climacteric women, of Quindío

\begin{tabular}{llllll}
\hline Dominion & Median & SD & Minimum & Maximum & Sexual dysfunction (\%) \\
\hline Desire & 2,78 & 0,89 & 0,81 & 3,97 & 78,65 \\
Arousal & 3,51 & 0,84 & 0,87 & 4,88 & 58,53 \\
Lubrication & 3,17 & 0,78 & 0,75 & 4,69 & 57,92 \\
Orgasm & 3,76 & 0,93 & 0,78 & 4,46 & 26,82 \\
Satisfaction & 2,84 & 0,86 & 0,65 & 4,37 & 28,04 \\
Pain & 3,89 & 1,57 & 0,96 & 4,98 & 66,46 \\
Total score & 19,95 & 5,87 & 4,82 & 27,35 & \\
\hline
\end{tabular}

Of the total population, $53.86 \%(n=265)$ had severe deterioration of four or more domains; and only $15.65 \%$ showed deterioration of two or less of the domains. The median sexual dysfunction per woman was 3 , which was present in $67.27 \%$.

Of the women, $71.74 \%$ showed total FSFI-6 scores equal to or lower than 21. It was observed that the score in FSFI-6 was higher in younger women and in HRT users. The score was also higher in those women who reported spontaneous sexual intercourse and in those who used erotic toys. Older women had a higher prevalence of dysfunctions, associated with lower scores in the FSFI-6.

Of the women, 387 (78.65\%) who had sexual dysfunctions, $38.75 \%$ $(n=150 / 387)$ reported with more than five years with a sexual disorder, of which only $24.66 \%(n=37 / 150)$ stated having received some type of treatment; However, $89.22 \%(n=439)$ complained that their sexual health was never evaluated during the consultation with the doctor (specialist or not). $4.67 \%$ reported that they were asked, at least once, about their sexual health in consultation with a specialist, and in $2.23 \%$ when in consultation with a generalist. $59.75 \%$ were interested in health professionals to start a conversation about sexuality in older women. $60.56 \%$ said the partner had a sexual dysfunction.

Regarding the symptoms of menopause, $86.78 \%$ reported sleep disorders, 71.74\% physical-mental fatigue, $80.89 \%$ muscle/joint discomfort. $72.96 \%$ mentioned heat waves. A significant presence of sexual problems was evident: $76.82 \%(n=378)$ affirmed less intensity during the orgasm, as well as greater difficulty in achieving it; $44.51 \%$ $(n=219)$ expressed that intercourse produced feelings of displeasure, $62.19 \%(n=306)$ reported that they felt discomfort when talking about sexuality issues. $60.36 \%(n=297)$ emphasized disagreement with their physical appearance after menopause, and 29.87\% $(n=147)$ assured that this aspect had a negative influence on their sexual relations.
$73.57 \% \quad(n=362)$ complained of symptoms compatible with menopausal genitourinary syndrome (SGUM), among which the following stand out: dyspareunia $(66.46 \%)$, vaginal dryness $(64.22 \%)$ and dysuria $(59.55 \%)($ Graph 1). $70.93 \%(n=349)$ reported that the SGUM had a negative impact on sexual satisfaction. Only $48.17 \%$ had visited a specialist because of the symptoms of the SGUM.

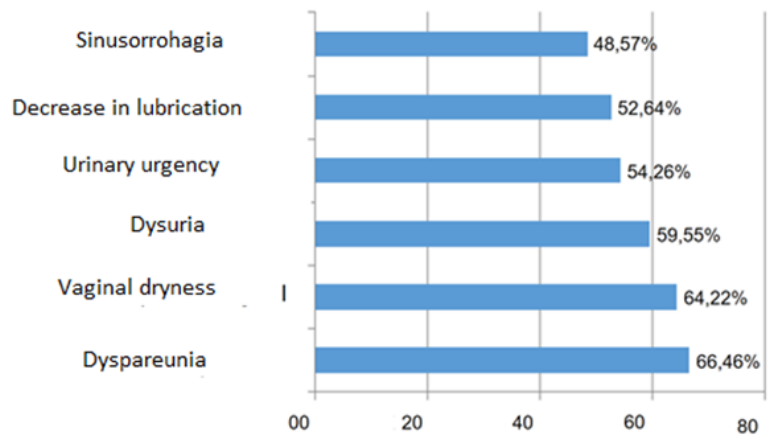

Graph I Prevalence of symptoms of genitourinary syndrome in women of Quindío.

\section{Discussion}

In this study we make a diagnostic approach to establish the prevalence of sexual dysfunctions in climacteric women of Quindío. A prevalence of $78.65 \%$ in sexual dysfunctions was found. They were mainly characterized by difficulties with sexual arousal $(78.65 \%)$ and pain/dyspareunia $(66.46 \%)$, while $71.95 \%$ reported sexual dissatisfaction. The FSFI-6 score in the affected population was $17.49 \pm 5.26$ points, while in the general population, the score was $19.95 \pm 5.87$ points. The involvement of two or less of the domains was uncommon (15.65\%). 
The prevalence in this study is higher than that reported by Espitia et al. ${ }^{18}$ in samples collected in the Coffee Axis in 2016, which report a prevalence of $42.9 \%$, in a population of 20,268 women. The difference could be explained because in this study the samples were analyzed with women exclusively in climacteric. Our results also differ from those reported by Sierra et al. ${ }^{19}$ in Medellin in 2016, which found $51.3 \%$ of low scores in the FSFI-6; however, they are similar to the $73.2 \%$ reported in India by Song $\mathrm{SH}$ et al. ${ }^{20}$

In relation to sexual desire, the reports of this research are higher than $58 \%$ published by Blumel et al. ${ }^{21}$ for Latin America in middleaged women, or $34 \%$ described in Europe by Nappi et al. ${ }^{22}$ and $62.6 \%$ described in Iran by Beigi et al. ${ }^{23}$ however, it is similar to $77.2 \%$ reported by Singh et al. ${ }^{24}$ in India.

The results of pain/dyspareunia, from our study, differ from the $34.6 \%$ reported by Song et al. ${ }^{20}$ and $34.9 \%$ of Beigi et al., ${ }^{23}$ but similar to $64.4 \%$ reported by Singh et al. ${ }^{24}$ although remarkably higher than $44.4 \%$ published by Serpa et al. ${ }^{25}$ in a study conducted in Bogotá in 2009 , in a population of 423 women, whose age ranged from 45 to 62 years.

The difficulties with orgasm are less than described in a systematic review published by Hayes et al. ${ }^{26}$ which mention $35 \%$ for orgasmic difficulties, and much less than $59.09 \%$ described by Espitia et al. ${ }^{27}$ in a group of 132 female doctors of the Colombian Coffee Axis.

Regarding other sexual dysfunctions, our results were inferior to those reported by Eftekhar et al. ${ }^{28}$ those who published $70 \%$ for excitation disorders and $70 \%$ for lubrication; however, they are higher than $49.0 \%$ (excitation) and $37.0 \%$ (lubrication) described by Song et al.; ${ }^{20}$ This is explained by the socio-demographic characteristics of the population, as well as the average age, the sample size, and the selection criteria.

When analyzing the influence of the symptomatology of the genitourinary syndrome of menopause, involving sexuality of the women of this study, the prevalence of sexual dysfunctions, is superior to that published by Pastore et al. ${ }^{29}$ in Charlottesville (Virginia), and inferior to that described by Karakoç et al. ${ }^{30}$ in Turkey, but similar to that reported by Espitia et al. ${ }^{9}$ in a population of 558 women from Quindío, of similar socio-demographic characteristics.

The percentages of the symptoms related to the menopausal transition present in this study remain in line with what described by Monterrosa et al. ${ }^{31}$ and Sierra ${ }^{19}$ in the Colombian population.

Given the outlook presented with these results, where more than $75 \%$ of climacteric women, have sexual disorders, we invite doctors and health personnel in general, to routinely investigate the sexual conflicts of mature women. And being aware that in Colombian women there is a prevalence of sexual dysfunctions close to the $1 / 3$ part of the population, mainly characterized by disorders in arousal and orgasm, ${ }^{32}$ the study of sexual problems in the climacteric is practically mandatory.

The research has the limitations that arise in cross-sectional studies; likewise, it was carried out in women recruited from the medical office. Among the strengths it is highlighted that it was done with a specific population sampling in a representative and heterogeneous sample in the socio-demographic; therefore, the results can be extrapolated to the other population groups in the country. Due to the significant percentage of sexual dysfunctions present in the climacteric women of Quindío, which apparently the medical community ignores; more research is necessary, especially in populations with less opportunity to visit a sexology specialist. The screening of sexual difficulties in older women should be part of primary care in order for them to be addressed by nurses and doctors, for prompt intervention.

\section{Conclusion}

The influence of menopause on the appearance of sexual dysfunctions in the elderly woman is unquestionable. This research shows that $75 \%$ parts of the population of climacteric women with sexual dysfunctions, characterized mainly by difficulties with sexual arousal and pain/dyspareunia.

Health professionals must open spaces for climacteric women, give them the opportunity to talk about their sexuality, which would contribute to the early detection of their sexual conflicts and concerns

\section{Acknowledgments}

To my beloved wife, Dr. Lilian Orozco Santiago, for actively participating in the analysis and relocation of each of the results.

\section{Funding}

The study was funded with the authors own resources.

\section{Conflicts of interest}

The authors declare there are no conflicts of interest.

\section{References}

1. Barentsen R, van de Weijer PH, van Gend S, et al. Climacteric symptoms in a representative Dutch population sample as measured with the Greene climacteric scale. Maturitas. 2001;38(2):123-128.

2. Utian WH. Ovarian function, therapy-oriented definition of menopause and climacteric. Exp Gerontol. 1994;29(3-4):245-251.

3. Menopause and Postmenopause Working Group. Clinical practice guideline of menopause and postmenopause. Spanish society of gynecology and obstetrics. Spanish association for the study of menopause, spanish society of family and community medicine, Iberoamerican Cochrane Centre. Barcelona; 2004.

4. Baber RJ, Panay N, Fenton A. 2016 IMS Recommendations on women's midlife health and menopause hormone therapy. Climacteric. 2016;19(2):109-150.

5. Harlow SD, Gass M, Hall JE, et al. Executive summary of the Stages of Reproductive Aging Workshop + 10: addressing the unfinished agenda of staging reproductive aging. Menopause. 2012;19(4):387-395.

6. Vásquez Awad D, Palacios S. Menopausia: UNA visión clínica. Primera edision. Bogotá. 2016;1(4):75-84.

7. Palacios S, Henderson VW, Siseles N, et al. Age of menopause and impact of climacteric symptoms by geographical region. Climacteric. 2010;13(5):419-428.

8. Rao TS, Nagaraj AK. Female sexuality. Indian $J$ Psychiatry. 2015;57(Suppl 2):S296-S302.

9. Espitia-De La Hoz FJ. Prevalence of genitourinary syndrome of menopause and impact on sexuality of women in Quindío (Colombia), 2013-2016. Rev Colomb Obstet Ginecol. 2018;69(4):249-259.

10. McKinlay SM, Brambilla DJ, Posner JG. The normal menopause transitions. Maturitas. 1992;14(2):103-115. 
11. Avis NE, Stellato R, Crawford S, et al. Is there an association between menopause status and sexual functioning? Menopause. 2000;7(5):297309.

12. World Health Organization (WHO). Defining sexual health: report of a technical consultation on sexual health. Geneva: WHO; 2006:28-31.

13. Espitia-De La Hoz FJ. Unlimited Sex/The flight to a more pleasant sexuality. Primera edision. Editorial Bolivar. 2015;2(15):181-85.

14. Isidori AM, Pozza C, Esposito $\mathrm{K}$, et al. Development and validation of a 6-item version of the female sexual function index (FSFI) as a diagnostic tool for female sexual dysfunction. J Sex Med. 2010;7(3):1139-1146.

15. Rosen R, Brown C, Heiman J, et al. The female sexual function index (FSFI): a multidimensional self-report instrument for the assessment of female sexual function. $J$ Sex Marital Ther. 2000;26(2):191-208.

16. Espitia- De La Hoz FJ. EROS device in the management of female anorgasmia: Prospective case series study in women of Quindío. Univ Salud. 2019;21(1):38-47.

17. Chedraui P, Pérez-López FR, Sánchez H, et al. Assessment of sexual function of mid-aged Ecuadorian women with the 6-item Female Sexual Function Index. Maturitas. 2012;71(4):407-412.

18. Espitia-De La Hoz FJ. Prevalence of sexual dysfunction in women of the coffee axis. Rev cienc biomed. 2016;7(1):25-33.

19. Sierra Londoño B, Echeverri Ramírez MC, Raigosa Londoño G Prevalence of menopausal symptoms, dyslipidemias and sexual problems in menopausal women in Medellín, Colombia. Rev Col de menopausia. 2016;22(3):25-32.

20. Song SH, Jeon H, Kim SW, et al. The prevalence and risk factors of female sexual dysfunction in young Korean women: an internet-based survey. J Sex Med. 2008;5(7):1694-1701.

21. Blumel JE, Chedraui P, Baron G, et al. Sexual dysfunction in middleaged women: a multicenter Latin American study using the Female Sexual Function Index. Menopause. 2009;16(6):1139-1148.
22. Nappi RE, Nijland EA. Women's perception of sexuality around the menopause: outcomes of a European telephone survey. Eur $J$ Obstet Gynecol Reprod Biol. 2008;137(1):10-16.

23. Beigi M, Fahami F. A Comparative study on sexual dysfunctions before and after menopause. Iran J Nurs Midwifery Res. 2012;17(2 Suppl 1):S72-S75.

24. Singh JC, Tharyan P, Kekre NS, et al. Prevalence and risk factors for female sexual dysfunction in women attending a medical clinic in south India. J Postgrad Med. 2009;55(2):113-120.

25. Serpa Fonnegra MP, Ramírez Bojacá ÉE. Sexuality and menopause: a study in Bogotá (Colombia). Rev Colomb Psiquiat. 2009;38(1):85-98.

26. Hayes RD, Bennett CM, Fairley CK, et al. What can prevalence studies tell us about female sexual difficulty and dysfunction? J Sex Med. 2006;3(4):589-595.

27. Espitia-De La Hoz FJ. Evaluation of the prevalence of sexual dysfunction in female doctors, of the Colombian Coffee Axis, in the climacteric stage. Arch Med (Manizales). 2017;17(1):70-77.

28. Eftekhar T, Dashti M, Shariat M, et al. Female sexual function during the menopausal transition in a group of Iranian women. J Family Reprod Health. 2016;10(2):52-58.

29. Pastore L, Carter R, Hulka B, et al. Self-reported urogenital symptoms in postmenopausal women: women's health initiative. Maturitas. 2004;49:292-303

30. Karakoç H, Kul Uçtu A, Özerdoğan N. Genitourinary syndrome of menopause: effects on related factors, quality of life, and self-care power. Menopause Rev. 2019;18(1):5-22.

31. Monterrosa-Castro A, Durán-Méndez LC, Salguedo-Madrid M Menopausal manifestations and quality of life in afro-colombians. Valuation whit Cervantes scale. Iatreia. 2017;30(4):376-390.

32. Espitia-De La Hoz FJ. Prevalence and characterisation of sexual dysfunctions in women, in 12 Colombian cities, 2009-2016. Rev Colomb Obstet Ginecol. 2018;69(1):9-21. 